\section{responsabilidade social da empresa}

1. Introdução;

2. O que é hoje concebido como responsabilidade social das empresas, 3. A estrutura básica da ideologia vigente e sua incoerência com uma relação social responsável; 4. O que é ser socialmente responsável.

\section{Responsabilidade social das empresas e ação política dos indivíduos e da sociedade}

Iliana Maria Michel Magalhães Do CMA/Face/UFMG

\section{INTRODUÇÃO}

O que é hoje conhecido como responsabilidade social das empresas? Como ela deve ser "realizada"?

Ao dedicar horas a fio à leitura de um material farto e disperso sobre a matéria, vejo-me diante de mais uma "moda". Está um pouco prejudicada agora com a crise econômica, mas potencialmente "promissora". São autores surgidos de bons cargos das organizações, saídos de cursos de pós-graduação, ou doutorado, imbuídos de leituras do processo político e social do Brasil e do mundo, sabedores do estágio atual de negociação entre as sociedades avançadas e suas organizaçðes. Sabendo que as "estratégias de recusa" dos operários brasileiros progridem. apesar de anos a fio de castração, de opressão, de silêncio forçado, de ameaças ao próprio corpo, à própria subsistência. Que estes fazem uso do seu poder como escravos de um regime, a partir da consciência que o "senhor capital" subsiste graças ao "senhor escravo". A relação somente persiste porque as duas partes têm interesse recíprocos em jogo. E portanto cada qual tem o seu poder.

Ao ver, no entanto, a potencialidade desta classe, apressam-se os autores a criar mecanismos "inovadores", adaptativos, para rapidamente reduzir estas pessoas que brotam a meros objetos de uso, novamente. E o grande capital é indiscutivelmente esperto, astuto e poderoso para fazê-lo. E o que faz são pequenas concessōes, alguns arranjos de participaçóes, vernizes "democráticos". E divulgam as medidas como "concessões", como criação própria, corno "avanços". Escondem todo o processo, toda a conquista da classe trabalhadora, que esta na base destas "concessões". Elas não são mais comunicadas como conquistas. E novamente a sociedade, especialmente a classe trabalhadora, so ouve a versão da história contada pelos dominadores. Não fica assim consciente da sua própria força, para usá-la como base para crescentes conquistas. Não há espaço para a apropriação dos frutos dos seus próprios esforços. Continua assim na postura e na consciência de ser frágil diante das instituiçőes instaladas, da ideologia vigente, da autoridade. E, assim, se submete passiva ao "mais forte".

A moda está criada: responsabilidade social das empresas. $\mathrm{E}$ isto vai longe. Responsabilidade com os empregados, como consumidor, com o fornecedor, com o meio ambiente etc.

E criam-se técnicas. ' A questão que me coloco é a incompatibilidade entre a cultura e valores atuais que sustentam toda a estrutura econômica e social das organizações e esta questão de responsabilidade social.

Como uma empresa que tem nas suas bases valores que definem a sociedade como fonte de trabalho e consumo pode assumir, responsavelmente, uma questão de tal ordem?

E por que "técnicas" vão solucionar uma incoerência como esta? E por que esta moda? Não seră esta a questão mais verdadeira? Por que esta moda? Eu sinto gosto de autoritarismo, de paternalismo em ioda esta linguagem. E junto com isto, porque é inseparável, vejo ingenuidade por parte dos autores e empresários quando tomo uma dimensão de tempo mais amplo. Em nossa história mesmo, nestes 20 anos de "Revolução". Tanta solução "empacotada", ajustada racionalmente ao que existe de "mais certo", e hoje temos um país que carece de coesão social, falido, com sérios problemas em todas as esferas, com corrupção incontrolável.

Autoritarismo porque quem dá a partir do seu próprio punho, do seu próprio saber e agir, respostas às questões sociais está impondo a muitos o que é o seu modo de ver, pensar e agir. Está se antecipando ao processo, temendo o próprio processo. Antes que a cada indivíduo da sociedade seja dado espaço para uma consciência como cidadão e pessoa humana, eu espertamente me antecipo, the adoço a boca, e the calo o ser por mais algum tempo. Nós temos medo do indivíduo consciente como pessoa e como coletividade. Cada um que ocupa o poder sabe que sobrevive graças à mutilação desta consciência.

Ingenuidade, porque até quando esta consciência permanecerá inerte, tal qual eu desejo e necessito? Eu sei que o controle que tenho me foge à cada instante. Por isso é que.os regimentos disciplinares se sofisticam. Ingenuidade porque eu julgo poder ter este controle por alguns teinpos. Eu me convenço de que todos acreditam em mim. Que o poder econômico será sempre mais potente do que as tentativas de cidadania. Que o homem cede sempre a alguns "favores". Ingenuidade porque pre. firo abafar as tentativas de negociação, de manifestação, de desagravo, do que dar-lhes crédito, como parte inerente da natureza humana, do social. Não vejo o fosso 
sendo criado. E como autor da "moda", como seu executor, sou também seu objeto. Pois os valores inculcados por esta cultura não minam apenas os dominados, levam junto os dominadores, como partes inseparáveis de um todo, que é hoje a nossa sociedade. Levam junto como? É fato que um trabalhador, do ponto de vista material, tem uma qualidade de vida, de forma geral, muitas vezes inferior ao seu empresário, ao seu gerente. Mas há um ponto em que todos nós pagamos um preço semelhante. Na medida em que os valores que norteiam o nosso sentido de vida não são substantivos, mas apenas de consumo, status, poder e reconhecimento.

Diante destas reflexões, às quais não pretendo dar caráter "original", "partidário", sensacionalista, quero deixar dúvidas e questōes sobre esta moda de responsabilidade social das empresas. A meu ver, a questđo é socialmente muito mais ampla. Trata-se de uma sociedade sem consciência, sem espaço para uma ação política responsável em todos os níveis. Uma sociedade objeto de uma ideologia que mutila cada um de nós, na nossa dignidade, como pessoas humanas.

Quando digo que não pretendo ser original, é porque este tema vem sendo longamente debatido, refletido, sob outros títulos, por quantos se dispðem, têm ânimo de ouvir a pulsação própria, das pessoas que os cercam e da sociedade, e ir até onde o "porquê" possa ser explorado. Não se contentando mais com as denúncias que no imediato permitam uma "reforma", um "rearranjo", uma "acomodação". Eu acredito que, para a mudança, o básico é a consciência posśvel. Não acredito em mudanças revolu cionárias no poder, no controle das instituições. A História nos tem mostrado que estas alterações são apenas alterações e não revolucionam de fato as relações entre os homens. Seria absurdo estar advogando em nossos tempos a eliminação do empresário, do empreendedor, do capital, da produção, do consumo. Eu questiono uma cultura, um modo de ser e relacionar de cada trabalhador, cada empresário, consigo próprio, e com os próximos, com a comunidade. É nada substantiva esta relação. É imediata, e objetal. Eu advogo uma mudança constante na consciência da qualidade de vida que tem cada um, que cada um submete a outros, e no crescimento lento e gradual desta qualidade. Eu me reservo a responsabilidade de ser crescentemente consciente, e de explicitar o que me for possível. Evitando a tentação autoritária, impaciente e ingênua de dar as "dicas" das formas rápidas, prontas e descartáveis de solução dos conflitos entre indivíduos, organizaçôes, sociedade, e vice-versa. Não sei se conseguirei.

\section{O QUE E HOJE CONCEBIDO COMO RESPONSABILIDADE SOCIAL DAS EMPRESAS?}

Em todos os países do mundo, hoje, quer seja um país de regime capitalista, ou comunista, quer seja um país desenvolvido ou não, fala-se em deteriorização da qua. lidade de vida do homem pelo processo industrial. Poluição, destruição de reservas naturais não-renováveis, alteraçð̃es climáticas, precipitaçð̋es na atmosfera. A qualidade de vida interior do homem, que foi inteiramente vasculhada, moldada, violentada. Fala-se do avanço da capaci- dade do homem de produzir formulas e mecanismos de destruição, que levarão d morte homens, animais e vegetação.

Diante desta realidade, há homens, grupos, classes, que reagem conscientemente. Falam, conscientizam, revelam. Outros, calados, se opðem, dizem não consciente ou inconscientemente. Estes estão no seu limite de doação e se negam a serem mais violentados.

Outros temem que seja destruída a própria fonte de riqueza. Ou seja, que a galinha dos ovos de ouro seja morta. E esta fonte é a passividade do trabalhador, a matéria-prima, a disposição da coletividade para servir.

Dependendo do grau de consciência, da qualidade de vida, da nutrição, da satisfação de necessidades, estas sociedades se rebelam, se manifestam, cruzam os braços para o trabalho servil, vâo à luta, à greve, à manifestação, à negociação.

A história do capitalismo não pode ser contada ape. nas pelas descobertas cientificas, pelas conquistas de mercado, pelos produtos aperfeiçoados, pelos avanços gerenciais. Isto é negar-lhe a face da sua interação social. A luta dos trabalhadores, as manifestações sociais contra abusos ecológicos deram um perfil próprio, particular, nesta interação. Muitos dos avanços devem-se inclusive a estas reações contrárias, como fruto de uma negociação inevitável. E quanto mais desenvolvida e suprida é a sociedade mais esta marca é explícita.

E desta interação que ao final do século XIX surgiram importantes doutrinas sociologicas e politicas, desenvolvidas por homens, hoje celebres, como Marx, Engels, Fourier, Proudhon. Surgiram, no inf́cio deste século, revolucionários como Lenine, Trotski, Rosa de Luxemburgo, Stalin, Durakin.

Com o avanço da complexidade das organizações, a divisão excessiva do trabalho industrial, a burocratização, aniquilando a identidade da relação das organizações com a sociedade, levaram ao surgimento de um extenso trabalho sobre o tema de sociologia industrial, que, segundo B. Monthez, é "um manifesto antiburocrático". Elton Mayo, nos EUA, iniciando experiências tipo tayloristas, buscando aperfeiçoar mecanismos para aumento da produtividade, "descobre" que a questão é humana, social, tambem. Dando com tal "descoberta" um novo rumo às crenças que orientavam o capitalismo, iniciando o desfecho de todo um arsenal de doces manipulaçбes para aumento da produtividade. Por outro lado, tal moda faz surgir exploraçðes sobre as relaçðes humanas de trabalho significativas para a consciência política do trabalhador e para a consciência do dirigente, despertandoo para o fato de que as relaçóes de trabalho têm fatores emocionais tão complexos quanto fatores racionais.

Nesta fase atual em que vivemos, o capitalismo é caracterizado pelo avanço tecnológico sofisticado, pela automação, pelas multinacionais. Este avanço caminha junto com o avanço da consciência política das sociedades desenvolvidas. A sofisticação da tecnologia é estimulada em parte por este fato, como uma estratégia de adaptação, de contenção da influência do social sobre a produção. Pois hoje as organizaçðes, nestas sociedades, têm que conviver com trabalhadores de forma mais participativa, mais integrada, mais negociada. 
$O$ avanço do capitalismo tem suas bases no avanço do social. São duas faces de uma mesma realidade, uma moldando a outra.

E fato que o poder dos capitalistas, especialmente os grandes, sua força criadora e manipulativa se sobrepõem à natureza humana do social; $\mathfrak{e}$ fato que este engole fumaça anos a fio, antes de rebelar-se. Mas rebela-se.

Assim é que responsabilidade social das empresas assume seus conteudos atuais, que aceitando como inevitável o avanço do capitalismo, mas também, com ele, o avanço social, a destruição da natureza humana, animal e vegetal, sugere medidas conciliadoras. Nestas medidas, estabelece uma compatibilidade maior entre os interesses do capitalismo e as necessidades primárias dos que the servem, e dos quais depende a sua sobrevivência. Com isto, alimenta a expectativa de conseguir maiores ganhos, maiores disponibilidades, maior docilidade. Mas estas mesmas medidas são as primeiras a serem cortadas em caso de crise financeira, baixa na margem de lucro. 0 que se faz é caridade.

São poucos os trabalhos sobre o tema de responsabilidade social que conclamam o empresário a assumir seu papel de cidadão. A responsabilidade social é na maioria das vezes tratada como "um bom negócio", onde, se o empresário der $x$, conseguirá $x+y$ de retomo. Outras vezes, assume o caráter do inevitável. Ou gasta-se ou se está ameaçado. A realidade ai está, inadiável, adapte-se a ela ou morrerá. Poucos se atêm a denunciar, a validar as solicitaçðes sociais, o direito de dignidade do trabalhador, de saúde, de qualidade de vida. Não denunciam o que está nas bases desta situação, os valores que sustentam $e$ que contribuem para a sua manutenção, a dificultação de soluções verdadeiras das questões mais prementes.

\section{A ESTRUTURA BÁSICA DA IDEOLOGIA VIGENTE E SUA INCOERENNCIA COM UMA RELAÇÃO SOCIAL RESPONSÁVEL}

Os pilares que sustentam, que são a fonte de vida contrnua do capitalismo são:

- o culto da autoridade;

- a manipulação e imposição das necessidades humanas; - o mito da neutralidade da ciência e da técnica.

Estes pilares não são colocados no "contrato de trabalho", não são explicitamente comunicados como condição. Eles estão hoje nas moléculas de cada um de nós. São resultados de um trabalho celular e secular. Que começa em casa, com os pais, com a religião, progride na escola, na universidade, e é mantido nas relaçőes de trabalho e nas relações sociais.

Desde a nossa infância nos é ensinado que devemos "respeito", "obediência" às autoridades, sem discutir. E durante toda a nossa vida isto é reforçado. Mudam as figuras, os discursos, os objetivos, mais conservamos a nossa postura submissa, ao que é "lei", "valor", "ordem", "norma", "certo", "errado", "direito", "justo". Não importa nunca o que, do interior de cada um, é negado, ño-adaptado, não-consistente com o estabelecido. E dar que surgem os "loucos", os "esquerdistas", "os rebeldes", "os indisciplinados". E somos desde crianças presenteados de alguma forma por nos "adaptar", ou com uma aprovação explícita, um olhar, uma carícia, uma ausência de repreensão, de repressão, de violentação.

E assim estamos sendo preparados para servir a toda e qualquer "autoridade", a qual depende da nossa adesão passiva e incondicional. Porque nâo nos é ensinado que podemos exercer a autoridade negociando, ouvindo, errando, tentando de novo. Não. A autoridade é autocrática, e o trabalhador é submisso, deverá estar pronto para servir. Mas há um porquê para isto.

Primeiro, para trabalhar em atividades alheias ao prazer do labor, em atividades que dilaceram a saúde física e mental, a identidade, a criatividade, a mobilidade, o humor. Em uma relação onde o seu trabalho, a sua criatividade, é de propriedade alheia. Depois, este trabatho se realiza alem da sua capacidade física e mental. E não the rende em dinheiro o suficiente para alimentar-se e habitar condignamente.

E tem que obedecer cegamente, achar bom e correto, não ver os abusos explf́citos. Ou, se vê, deve calar para se proteger. Esta adesão passiva e incondicional é básica para realimentar continuamente o círculo do capitalismo, ou seja, trabalhar - produzir - consumir - e voltar ao mesmo ponto. Pois somos suficientemente estimulados a gastar sempre além das nossas possibilidades, gerando uma dependência sem fim do sistema. Este mito aparece em outras esferas das relações de trabalho, comprometendo a própria empresa. Deixa-se de fazer uma observação crítica, um alerta. Deixa-se de colocar uma nova idéia, com receio de ser "boba" ou reprovada. Teorias "inteiras" sâo engolidas e aplicadas porque o "fulano" disse, pesquisou, provou. Em tal país (EUA, por exemplo) "isto é largamente usado", e então é indiscutivel.

E este mito da autoridade que dá condiçðes para a existência do segundo pilar do capitalismo, que é a manipulação e imposição das necessidades humanas.

Ao homem é dito o que ele necessita para sobreviver. E estas necessidades estão sempre ligadas aos produtos produzidos e disponfveis para compra e consumo. Estas necessidades são criadas e aguçadas das maneiras mais grosseiras e sofisticadas (o que é a mesma coisa). Vemos pessoas esclarecidas trabalhando arduamente para pagar dívidas oriundas da aquisição do último carro, da última televisão etc. Agora, este homem obediente ja. mais se pergunta se precisa do que dizem que ele tem ne. cessidade. Dizem, está dito! E se oferece como objeto à ciranda do consumo, auto-alimentando um processo destrutivo, onde o que menos é esperado é a sua identi. dade, seu querer consciente, sua opçāo.

E neste processo que ele se escraviza. Coloca como razão de existir o consumo. Como meio, o trabalho. Como condição inevitável, a submissão. Está sempre sendo "dopado", artificialmente "animado", pela possibilidade de comprar isto e aquilo nos próximos meses. E muitas vezes, e para $80 \%$ da população do Brasil, o que ele consegue é comer e morar mediocremente.

0 terceiro pilar que sustenta o capitalismo e que tem como fonte a docilidade social é o mito da ciência e da técnica. E a autoridade do saber. Existe na socieda- 
de um sagrado culto à ciência e à tecnologia. A este sagrado é concedida toda a autoridade. Em nome deste pretenso saber, medidas as mais absurdas sāo tomadas, em detrimento da saúde ambiental, da dignidade do homem, da soberania do país. Os governos, os empresários tomam decisões autoritárias, protegidos pelo mito da racionalidade. Dentro de uma pretensa, certeza, em que, como disse Descartes, procura-se atingir "o saber e a verdade para nos tornarmos senhores e possuidores da natureza". "É neste enunciado do grande filósofo racionalista que vemos mais claramente a ilusão, a loucura, a absurdidade do capitalismo" (Castoriadis e Cohn-Bendit, 1981).

Mas para um homem que sabe que vai morrer, que sabe que é minúsculo diante da natureza, mas que no entanto foi criado em uma sociedade sob o mito da autoridade, vendo-se diante de um "senhor" que se diz capaz de eliminar todas as incertezas da vida, de combater a morte, a infelicidade, o desconhecido, é um prato cheio. O que é dito de forma racional, lógica, por quem tem o "saber", está dito. Cabe a cada um obedecer. E este "saber" distante, sagrado, torna-se um mito, acessível a poucos. $O$ sentir, a consciência sensorial, o óbvio, se esvaem como meros sentimentos sem fundamentação racional e científica. simples.

O palavreado emplumado é distante de uma vivência

Mas em que e para que este controle da natureza é possível e desejável? E esta a relação que queremos com a natureza? Ou a questão é outra? $\mathrm{E}$ por que os homens não vêem isto $e$, se vêem, por que não saem disto?

Primeiro, "porque eles precisam comer e sobreviver" (Castoriadis e Cohn-Bendit, 1981). E as formas instaladas na sociedade para que isto seja possível lhe antecederam, são fortes e estruturadas. Segundo, porque os valores do capitalismo prevêem a aquisição de uma gama infinita de bens, criando o seu próprio mecanismo autosustentador. Ele dá ao trabalhador a possibilidade e o sonho de conquistar estes bens, mas em troca de uma submissão às suas regras. $\mathrm{E}$ atrela o homem a ele. Como abrir mão de umas férias na praia, de um carro, de um restaurante, de uma roupa bonita?

Como questionar tudo isto diante de uma publicidade massificante, de uma oferta que tonteia? Como ter dúvidas se este é o sentido de viver, se é a qualidade de vida que se deseja? Que eu não quero trabalhar 50 horas por semana, mas talvez menos? Que o meu desejo e o meu dom são outros? É difícil. E, por outro lado, nunca se ganha o "suficiente". De tal forma que, pela sobrevivência mais "digna" (padrão burguês) e pela equiparação social mais alta, o homem tem sempre que trabalhar, que servir. Reforçando esta cultura, as organizaçðes estabelecem as cuidadosas estratégias disciplinares que visam conter a consciência, $a$ individualidade, a manifestação, o repúdio, que são assim chamadas de "indisciplinas". Estas são, no entanto, utilizadas somente naqueles pontos do comportamento humano onde os valores ainda não atuaram de forma eficaz. Cuidam, assim, de cercar a "preguiça", a "sociabilidade", a "recusa". Controlam os traba- lhadores nos seu movimentos, no seu corpo, no seu espaço e tempo. O lazer é pré-fixado em dias e horas.

Todas estas medidas, culturais e das organizaçðes, são tão eficazes que cada um de nós se vê em sentimento de culpa, em autocondenação, quando foge às "regras". Fazem-nos voltar atrás e nos acomodar. A nossa identidade é uma identidade capitalizada. Valemos pelos títulos, pelo emprego, pelos bens, pelo cargo. "Somos felizes detentores de um emprego" (Guerreiro Ramos, 1981). Quando o perdemos, com ele vai a nossa identidade, mesmo que economicamente estejamos acobertados. Sentimo-nos miseráveis, inúteis e alienados.

E toda uma estrutura cultural da sociedade contaminada. E o virus básico é a falta de autonomia do homem como ser, como indivíduo. A poluição básica, o problema ecológico básico que sofremos é a ausência de uma postura reflexiva, de uma consciência política. Uma consciência que reflita sobre o social, a partir do modo de ser próprio de cada um, o que se quer em termos de vida, o que se tem necessidade e desejo de consumir, qual é o meu espaço, o meu tempo. Qual é a minha identidade. Ao que me submeterei para realizar o meu modo de vida.

Mas esta é exatamente a maior ameaça: a autonomia do homem. Isto joga por terra as bases sobre as quais estão edificadas a economia, a ordem social as empresas.

E como então propor aos beneficiários maiores e diretos deste quadro, ou seja, aos empresários e tecnocratas, que tenham "responsabilidade social"? Para que mais? Eles perguntariam. Se "damos" emprego, salários, se produzimos, construímos, embelezamos? Se pesquisamos, descobrimos novas formas de proteção à vida, de controle da natureza, de fontes de prazer, de facilitação do dia-a-dia?

Mas, se questionados sobre as conseqüências, sobre o preço social de tal processo, apelam para a "neutralidade da ciência", a "autonomia" que cada um tem de optar pela sua própria vida, pela "inevitabilidade" dos fatos, das decisðes. É um discurso coerente, eficiente e fechado. Nele há resposta para tudo, desde que não se alterem os ganhos.

Há, portanto, uma estrutura de privilégios, de interesses, sustentados por uma "significação imaginária do saber e da técnica" (Castoriadis e Cohn-Bendit, 1981). As mudanças e adaptaçðes são frutos de acomodações inevitáveis. E quem provoca estas crises haverá sempre de ser a parte sufocada, oprimida, que consegue, em meio a todas estas estratégias cerceadoras da consciência e da manifestação críticas, se revelar e se rebelar. São as "brechas" (Castoriadis e Cohn-Bendit, 1981) da história da sociedade.

\section{O QUE É SER SOCIALMENTE RESPONSÁVEL}

Aqui não há como não apelar explicitamente para a filosofia e fazer-nos a pergunta central e eterna do homem: "O que é a vida humana? Vivemos para fazer o quê? Qual é o modo de vida e quais as necessidades? Que queremos nós?" (Castoriadis e Cohn-Bendit, 1981). E o momento de acreditarmos e utilizarmos a filosofia na sua missão de negatividade, de "depurar a reflexão sobre a 
condição humana de todas as ilusores que nela se depositaram ao longo dos séculos de triunfo da razão" (Pascal).

E quem, como, quando, a partir de que podem ser colocadas estas questões? De forma a respondê-las "ñ̃o com o saber absoluto, mas com conhecimento de causa e com lucidez" (Castoriadis e Cohn-Bendit, 1981). Fugindo à tentação de impor respostas, formas, projetos, pacotes, em desrespeito à autoridade, ao desejo de individuos, grupos, coletividade. Não faço aqui uma apologia ao "espontaneísmo", ao "assembleísmo". Isto è tomar o que digo pelo seu extremo. Eu falo de consulta, de respeito à posição do outro, na convicção de quem tem o problema tem junto com ele a solução melhor. E uma questão de deixá-lo expressar, elaborar, negociar e executar. E não precisa estender isto a todos. É impossível na maioria das vezes. E não funciona bem na primeira e segunda vezes. E um processo paciente, mas que é possível.

Uma sociedade que tenha como valor colocar continuamente estas questões, de assumir uma postura reflexiva, de agir conforme os limites do possível para as pessoas, as circunstâncias, caminha para uma saúde maior. $\mathbf{E}$ eu chanı de saúde um equilibrio entre a minha individualidade e a imposição externa, os limites do outro, da sociedade, da economia, da natureza, do avanço tecnológico.

Não vejo isto como simples e fácil. O que coloco é uma utopia. Eu só me valho do direito que tenho de imaginar, de fazer "renascer a relação esquecida e escondida da sociedade com a utopia. Utopia compreendida como desejo de mudança e horizonte da nossa atividade, sempre que se prejulgue a respeito da possibilidade de materialização desta mudança" (Castoriadis e Cohn-Bendit, 1981).

Sei que a realização desta utopia tem implicações profundas na ideologia vigente, na cultura vigente, na economia nos valores, nas relações dos homens entre si, com o Estado, as organizações, o poder, entre o homem e sua interioridade, suas necessidades, seus privilégios, seus sofrimentos.

E o balançar de toda uma estrutura ideológica, econômica e social, cujo sustento é a contradição básica desta proposta, ou seja, a ausência de consciência crítica.

Outra questão que me coloco é se os individuos querem isto, se têm vontade disto. Até que ponto o processo de aniquilamento da consciência crítica é intransponivel? Se eles criam os seus próprios "gens", que são transferidos ${ }^{\circ}$ de pessoa para pessoa, numa acomodação e estado de letargia, premidos socialmente?

Não cabe aqui perguntar se as pessoas são capazes. Porque são. Basta observar uma criança não submetida ainda ao processo de docilização. A pergunta que cabe é se nós queremos. Se o desejo de autonomia tem espaço para agir. Se estamos dispostos ao "desconforto" de existir, de dizer ño, de receber não. Se quem está no poder hierárquico está disposto ao trabalho paciente da negociação, ao labor do reconhecimento das diferenças, ao incômodo de ser contestado, criticado, relativizado, impossibilitado.

A consciência de que as conseqüências desta postura são desconhecidas, não-uniformes, não conformistas, mas continuamente revolucionárias. Implica reconhecer que o Estado, o empresário, o pai, o professor, qualquer "autoridade constituŕda" têm os seus limites. E quem os coloca é o trabalhador, o filho, o cidadão. E que ninguém é capaz, competente, para decidir sobre um modo de vida para os outros. Implica reconhecer que é de direito e saudável cada um expressar-se, articular-se, colocar-se contra ou a favor. Não existe o certo ou errado nas es. colhas individuais. São escolhas.

Para isto, do ponto de vista da organizaçăo da sociedade, ela teria que desfazer-se, gradativamente, de seus aparatos inibidores da consciência e da expressão.

E uma questão de "desfazer" e não de construir mecanismos. Ouvir quem executa, quem consome, quem reflete, quem produz. Cultivar o valor das diferenças de necessidades, de valores, de religião. Fugir à tentação paternalista e autoritária de massificação, de solucionador de problemas. Deixar que o processo cuide de ir suscitando seus problemas, suas soluçōes, seus erros.

Trata-se de abrir espaço ao debate, à manifestação, à expressão, à negociação através do desarmamento das estratégias mais fortes que contêm estas expressões. É deixar, confiando, que o próprio processo crie suas formas, suas cristalizações.

Tal processo balançará os pilares do capitalismo. É fato que aparecerão perturbaçōes à ordem estabelecida. E fato que dificultará a "ordem social", o controle social. Mas é fato que o esforço e a imáginação do "saber disciplinar" será poupado. É possível que as soluçðes sociais surgidas sejam mais criativas, mais compromissadas, menos dispendiosas e tragam mais qualidade de vida, mais comprometimento.

Se é possível isto nas correlaçð̃es de forças hoje estabelecidas, eu questiono.

Mas não me disponho a me tapear e falar de responsabilidade social de outra forma. Não é uma questão apenas das "empresas", "do governo". E uma questão essencialmente das pessoas, dos individuos, de grupos, de comunidades. É portanto uma questão política. E, como tal, é uma questão de cultura, de valores sociais.

Falar de responsabilidade social é atentar principalmente para o sofrimento que assola cada indivíduo. Despojado do seu sentir, do seu saber, da sua criatividade, do seu desejo subjugado por uma gama de necessidades infinitas, cujo preço de satisfação é todo o seu tempo, seu corpo, seu espaço.

Não quero aqui exprimir que eximo os empresários e o governo de serem socialmente responsáveis. Eu quero dizer que só acredito que o serão de fato a partir de quando houver por parte deles, como indivíduos e cidadãos, uma mudança contínua de postura diante das questões que coloco. Para si primeiro, para quem lhes é próximo, para sua empresa, para o município, estado ou país que dirijam. Contribuindo desta forma para a reconstrução lenta e gradativa de valores substantivos. Quero dizer, no entanto, que é saudável e imprescindível que haja iniciativa propria por parte de indivíduos, grupos, comunidades, setores das empresas. Pois mudanças, de modo geral, só ocorrem em estados de crise, em situa- 
çóes de sufocamento e alienaçao. E esta é a verdade mais proxima de quem está fora do poder.

Este um campo aberto à conceituação de qual é a responsabilidade social de cada um, como cidadão. Ou se trabalha neste campo arriscado, complexo e aberto, através de uma mudança pessoal diante das forças estabelecidas, diante de pessoas e grupos que nos cercam, diante da empresa que dirigimos, gerenciamos, ou estaremos manipulando, arranjando o objetivo de sermos responsáveis socialmente. Exercer a responsabilidade social é uma questão de sermos conscientes, usar e abrir espaço para a ação polftica. E superar o preconceito do ser polf́tico e ser cidadão.

Isto não é mais uma técnica. Como técnica é um fracasso. Se puder ser um processo de consciência, de mudança, há esperança. E não é uma questão de que, se os dirigentes e os técnicos não o fizeram, a sociedade nada poderá fazer. Ela fará, sempre faz.

E uma questão de sufocamento, de limite de tolerância do aniquilamento da dignidade. $O$ homem tem o poder de, em um estado de limite de sua identidade, se rebelar, se posicionar. E uma transformação de estado da consciência pelo limite. Pelo limite da dignidade, do estômago, da opressão. Toda sociedade vê hoje seus controles sociais, econômicos e fiscais serern solapados. Todos os países lidam hoje com economias paralelas tão grandes quanto a oficial. Lidam com manifestaçðes clandestinas, com boicotes à produção, com estratégias de recusa refinadas. E estas são tão maiores e graves quanto maiores são as tentativas de controle social. Esta busca de autonomia do indivíduo e da sociedade faz parte da natureza humana. A história é um suceder de relaçōes de senhores e escravos que se contrapõem, se alternam no poder de dominar.

Ela não precisa da concessão de uma classe com o seu saber, seu poder econômico, para manifestar-se. É uma questăo de tempo. Tempo tomado aqui em um sentido amplo, histórico, 15, 20, 25, 30, 100 anos.

Se o tèma é responsabilidade social, ele é amplo, de alto risco, de profundas raízes culturais, econômicas, sociais, ideológicas e multinacionais. Faz parte de um consenso universal, de privilégios poderosos. Mas que a partir da nossa individualidade, das nossas relações sociais, é uma opção viável.

Afirmaçбes como "este trabalho é de conteúdo ambíguo", "de cunho filosófico", “ideológico", e não é de utilidade prática, operacional, constituem um risco inerente que corro. A pergunta que tenho é se os que são "práticos", “operacionais", são adotados. Ou se são submetidos aos valores, interesses e possibtidades de quem os lê. Isto é, quando são lidos. Porque este é o outro risco.

Tive aqui o objetivo explícito de introduzir uma reflexão filosófica, ideológica e polf́tica. $\mathrm{Na}$ expectativa de sensibilizar os valores, interesses e possibilidades de quem porventura me leia. Agora, dentro de uma conviç̧ão de que a filosofia, a ideologia e a polftica existem, estão aí a nos orientar. $\mathrm{O}$ que diferencia as pessoas, quanto a elas, é o nível de consciência que têm de como são manipuladas por elas, e a qualidade da mudança consciente que operam em seus valores e açðes.
1 Ver "Responsabilidade social das empresas: uma visão operacional” (Paulo César Motta, PUC/RJ); “A participação nos lucros como fator de estímulo" (Revista Sociedade Industrial, mar. 1975); Balanço social das empresas (Lima Gonçalves, org., 1981).

\section{REFERENCIAS BIBLIOGRÃFICAS}

A Participação nos lucros como fator de estímulo. Revista Sociedade Industrial, mar. 1975.

Castoriadis, Cornelius \& Cohn-Bendit, Samuel. Da Ecologia à autonomia. São Paulo, Brasiliense, 1981.

Chauí, Marilena. O que é ideologia. São Paulo, Brasiliense, 1981 .

derna, 1982.

Guerreiro Ramos, Alberto. A Nova ciência das organizações. Rio de Janeiro, Fundação Getulio Vargas, 1981.

Habermas, Jürqen. Conhecimento e interesse. Rio de Janeiro, Zahar, 1982.

Jones, Thomas M. Corporate social responsibility. Califormia Management Review, 22 (2). 1980.

Lima Gonçalves, E., org. Balanço social da empresa, São Paulo, Biblioteca Pioneira de Administração de Negócios, 1980.

Lodi, João Bosco. Como o empresário deve lidar com a questão social. Exame, out. 1979.

Mazoni, Amnéris. A Estratégia da recusa: análise das greves de maio de 1978.

Minalin, José E. A Empresa brasileira e as perspectivas de mudança social. Belo Horizonte, FJP, 1979. p. 18. (Palestra proferida no Programa de Estratégia Empresarial para Altos Executivos.)

Motta, Paulo César. Responsabilidade social das empresas: uma visāo operacional. Rio de Janeiro, PUC, s.d. (documento preliminar).

$\mathrm{O}$ balanço social ainda é um instrumento pouco usado para medir os benefícios da empresa Tendências do Trabalho, jun. 1982.

O pesado fardo das despesas sociais. Revista Sociedade Industrial, nov. 1976.

Silva, Franklin Leopoldo. Artigo sobre "Pascal". Folha de São Paulo, 24 jul. 1983.

Toffler, Alvin. A Terceira onda. Rio de Janeiro, Record, 1982.

Volker, Paulo et alii. Revolução e autonomia: um perfil de Cornelius Castoriadis. Belo Horizonte, Cope, 1981. 